\title{
Comparison of early aftershock sequences for the 2004 Mid-Niigata and 2007 Noto Hanto earthquakes in central Japan
}

\author{
Jim Mori ${ }^{1}$, Yasuyuki Kano ${ }^{1}$, and Bogdan Enescu ${ }^{2}$ \\ ${ }^{1}$ Disaster Prevention Research Institute, Kyoto University, Japan \\ ${ }^{2}$ GeoForschungsZentrum, Potsdam, Germany
}

(Received July 17, 2007; Revised August 10, 2007; Accepted August 16, 2007; Online published February 19, 2008)

\begin{abstract}
We examined continuously recorded seismograms of the 2004 Mid-Niigata and 2007 Noto Hanto earthquakes to compare the early aftershocks for these two similar earthquakes in central Japan. Although the two mainshocks had similar size, depth, and focal mechanisms, the aftershock levels were quite different, with the Niigata case being much stronger. The results of our analyses show that the early aftershock occurrences for the two events were quite similar for the first several minutes. About 7 minutes after the Niigata mainshock, significantly enhanced aftershock triggering began and continued for the duration of that aftershock sequence. We speculate that the change that occurred in the Niigata region may be due to fluid effects in the fault zone.
\end{abstract}

Key words: Aftershocks, Mid-Niigata earthquake, Noto Hanto earthquake, triggering.

\section{Introduction}

With the improved recording of aftershock sequences, a number of recent studies have described and quantified the occurrence of aftershocks in the time immediately following the mainshock. For example, Kagan (2004) points out the deficiency of earthquake catalogs during this time period. Also, papers by Shcherbakov et al. (2004), Peng et al. (2006, 2007), and Enescu et al. (2007), report changes in the decay rate of aftershocks during the first several minutes after the mainshock. The changes in rates during the beginning of an aftershock sequence suggest the possibility of a number of physical processes, such as aseismic slip, rate and state friction, or fluid flow.

In this study, we compared the early aftershock occurrences for the 2004 Mid-Niigata $\left(M_{\mathrm{w}} 6.6\right)$ and 2007 Noto Hanto $\left(M_{\mathrm{w}} 6.7\right)$ earthquakes that occurred in central Japan. The two shallow earthquakes were located several hundred kilometers inland of the subduction zones that extend along the southeast coast of Japan, and had similar source sizes, faulting depths, and thrust-fault mechanisms (e.g., Aoki et al., 2005; Mori and Somerville, 2006; other papers in this volume). However, the aftershock sequences for the two earthquakes were very different. The 2004 Mid-Niigata earthquake had a very strong aftershock pattern that included $19 M_{\mathrm{j}} \geq 5.0$ and $120 M_{\mathrm{j}} \geq 4.0$ events during the first 10 days following the mainshock, while the 2007 Noto Hanto earthquake had a more typical pattern for events in Japan, with $3 M_{\mathrm{j}} \geq 5.0$ and $42 M_{\mathrm{j}} \geq 4.0$ events. The two aftershocks distributions spread out over roughly similar size areas (Fig. 1). For both sequences we examined the earliest identifiable aftershocks, to see if the difference in the level of aftershock activity begins from the time im-

Copyright (c) The Society of Geomagnetism and Earth, Planetary and Space Sciences (SGEPSS); The Seismological Society of Japan; The Volcanological Society of Japan; The Geodetic Society of Japan; The Japanese Society for Planetary Sciences; TERRAPUB mediately following the mainshocks, or if it evolves with time.

\section{Data and Methods}

We used the continuously recorded data from nearby HiNet stations (Fig. 1), operated by the National Institute for Earth Science and Disaster Prevention (NIED), to identify the early aftershocks following both mainshocks. Figure 2 shows the high-pass filtered seismograms for a representative station for each of the two earthquakes. The $5 \mathrm{~Hz}$ highpass filter was chosen to facilitate identification of the highfrequency arrivals from individual aftershocks. For the latter parts of the records, after about $500 \mathrm{sec}$, one can clearly see that there are more aftershocks on the Niigata record.

In a previous study (Enescu et al., 2007), six Hi-Net stations with epicentral distances of less than $30 \mathrm{~km}$ (Fig. 1) were examined to search for the aftershocks during the time immediately following the mainshock. For that case, the completeness magnitude was estimated to be $M_{\mathrm{j}} 3.4$. In this study, we used 6 stations distributed at similar distances. The station density for the Noto Hanto earthquake (Fig. 1) is roughly similar, although the mainshock was near the Japan Sea coast, so the azimuthal coverage is not as complete. Aftershocks were identified by looking at large printouts of the continuous records for the six stations and peak amplitudes were measured to calculate the magnitude. The magnitude determination using these high-pass filtered records was calibrated by using a set of 30 earthquakes that were also listed in the catalog of the Japan Meteorological Agency (JMA). The dotted lines on Fig. 2 show the approximate amplitude levels for $M_{\mathrm{j}} 3.5$ and $M_{\mathrm{j}} 4.0$ earthquakes, although this is a rough indication since there are large amplitude variations according to distance to the event. The events that were identified in this manner were cross checked and combined with the JMA catalog. The completeness level for the Noto sequence is estimated to be 


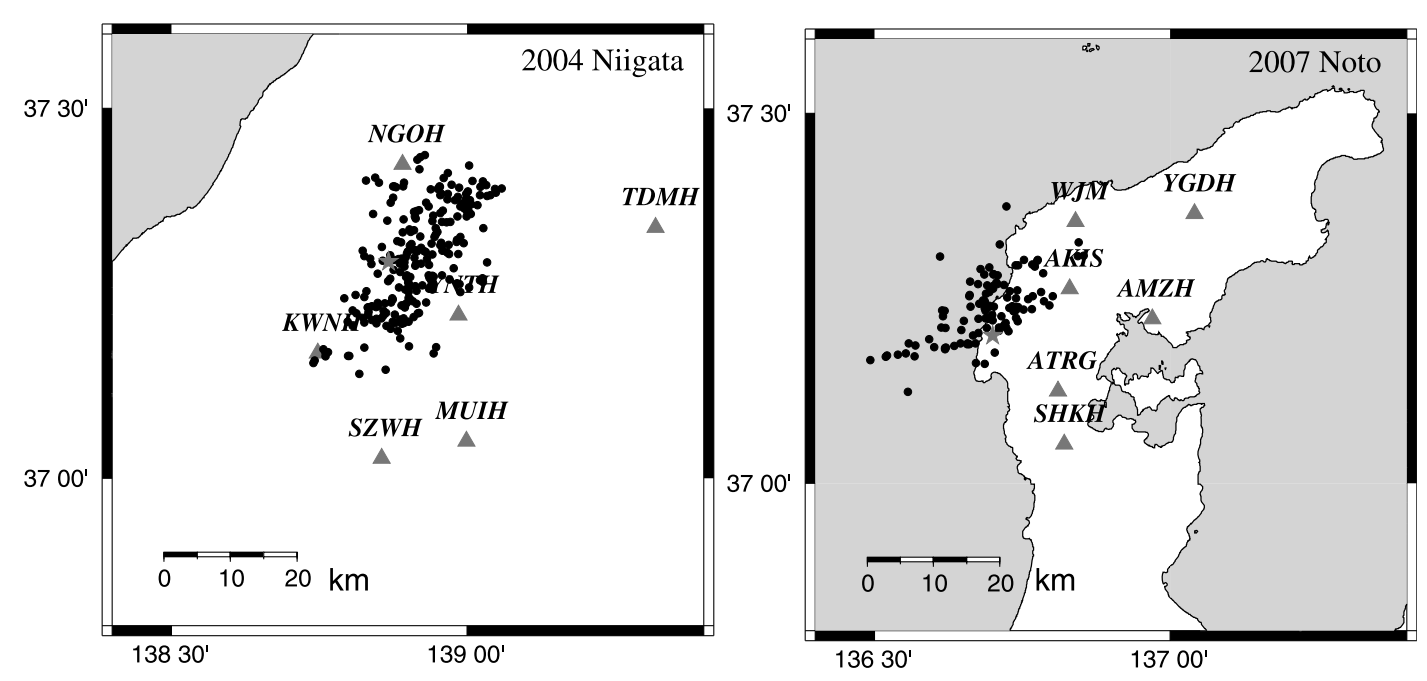

Fig. 1. Maps of aftershock and station distributions for the 2004 Mid-Niigata and 2007 Noto Hanto earthquakes used in this study. $M_{\mathrm{j}} \geq 3.5$ aftershocks that occurred during the first 10 days following the mainshock are plotted. Earthquake location data are from JMA.

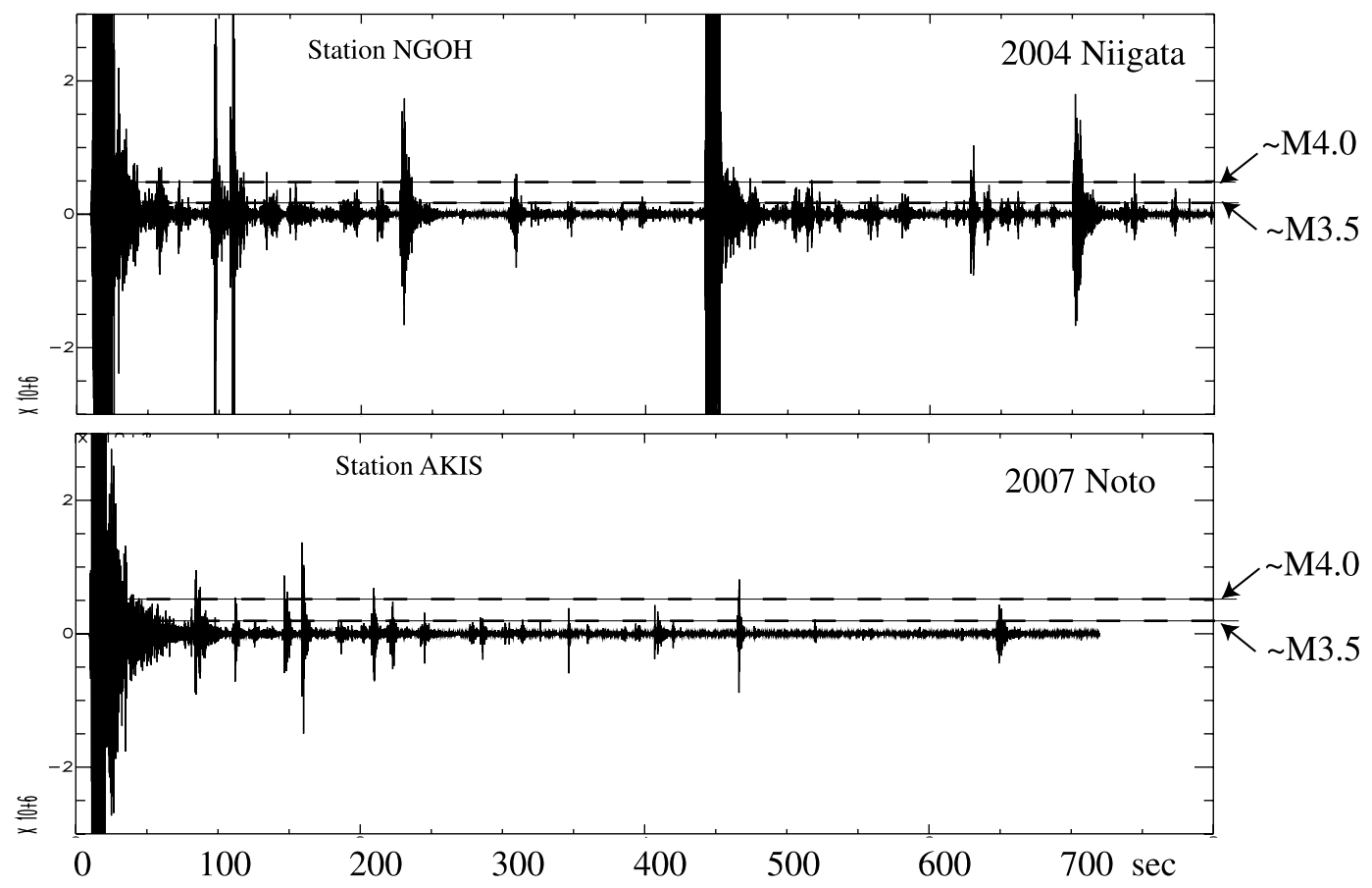

Fig. 2. Velocity seismograms high-passed filtered at $5 \mathrm{~Hz}$ for the early portions of the aftershock sequences. Following the large aftershock at about $440 \mathrm{sec}$ for the Niigata sequence, one can see a higher rate of aftershock activity. The locations of the stations NGOH and AKIS are shown in Fig. 1.

about $M_{\mathrm{j}} 3.5$ and is certainly complete at the $M_{\mathrm{j}} 4.0$ level.

\section{Results}

The cumulative numbers of aftershocks as a function of time for $M_{\mathrm{j}} \geq 3.5$ and $M_{\mathrm{j}} \geq 4.0$ events are shown in Fig. 3. The counting of aftershocks starts one minute after the mainshock origin time. It is possible to identify aftershocks prior to this time, but this delay ensures that we are making consistent counts for the two sequences. The event counts show that the aftershock sequences of the two earthquakes were quite similar for about the first 7 minutes. Following that time, the Niigata aftershocks clearly continue at a much higher rate which is about 3 times the rate of the Noto earthquake. The time the rates diverge corresponds to the occurrence of a $M_{\mathrm{j}} 6.3$ earthquake in the Niigata sequence. This pattern can be seen in both the plots for the $M_{\mathrm{j}} \geq 3.5$ and $M_{\mathrm{j}} \geq 4.0$ events. Since there are more earthquakes for the $M_{\mathrm{j}} \geq 3.5$ data set, the time resolution is better. The $M_{\mathrm{j}} \geq 4.0$ data set is also shown because we are confident that this data set is complete, as shown in Fig. 2, while there may be some questions about the completeness at the $M_{\mathrm{j}} \geq 3.5$ level. The change in the rate of aftershocks appears to occur about 7 minutes after the mainshock in the plot of $M_{\mathrm{j}} \geq 3.5$ events and after about 15 minutes in the plot of $M_{\mathrm{j}} \geq 4.0$ events.

The overall statistical properties of the two sequences are quite similar. Table 1 shows the $a$-values, $b$-values, and $p$ values calculated for 10 days of $M_{\mathrm{j}} \geq 3.5$ aftershocks, using 

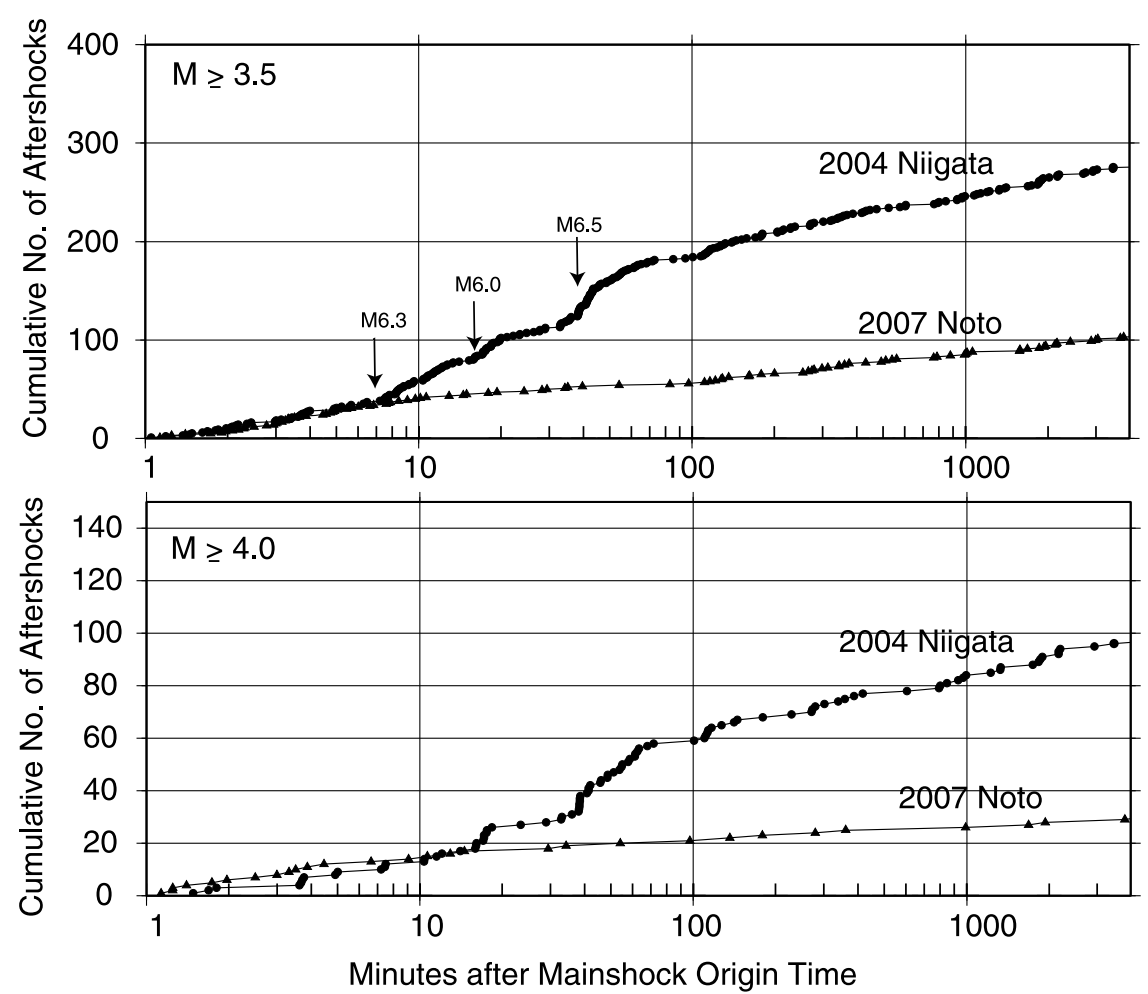

Fig. 3. Cumulative aftershock counts for $M_{\mathrm{j}} \geq 3.5$ (top) and $M_{\mathrm{j}} \geq 4.0$ (bottom) events of the 2004 Niigata and 2007 Noto earthquakes, starting 1 minute after the mainshock. Arrows shows the times of larger aftershocks in the Niigata sequence.

Table 1. Statistical parameters for the two aftershock sequences using 10 days of data for events $M_{\mathrm{j}} \geq 3.5$.

\begin{tabular}{lccc}
\hline & $a$-value & $b$-value & $p$-value \\
\hline 2004 Niigata & 5.8 & 0.94 & 0.99 \\
2007 Noto & 5.9 & 1.05 & 1.01 \\
\hline
\end{tabular}

the following standard equations.

$$
\log N=a-b \log M
$$

is the frequency-magnitude relation, where $N$ is the cumulative number of earthquakes with magnitude $M$ or larger (Gutenberg and Richter, 1944). The $a$-values and $b$-values were calculated using the maximum likelihood method (Aki, 1965). The frequency-magnitude data for the first 10 days of both aftershock sequences are shown in Fig. 4. There are a number of larger aftershocks in the Niigata sequence which cause deviations from the Gutenberg-Richter relation.

$$
\log N=k-p \log (t+c)
$$

is the modified Omori law where $t$ is time after the mainshock and $k$ is a constant (Utsu, 1961). The $p$-values and $c$-values were estimated using a grid search method. For the Noto sequence, it was difficult to resolve a significant delay to the beginning of the aftershock sequence and the estimates of the $c$-value depended on the time length of the data that was used. Using data for the first 1.5 hours, which show a clear smooth trend, gives a $c$-value of less than 1.5 minutes. Since the initial several minutes of the Niigata and Noto aftershocks look similar, this implies that

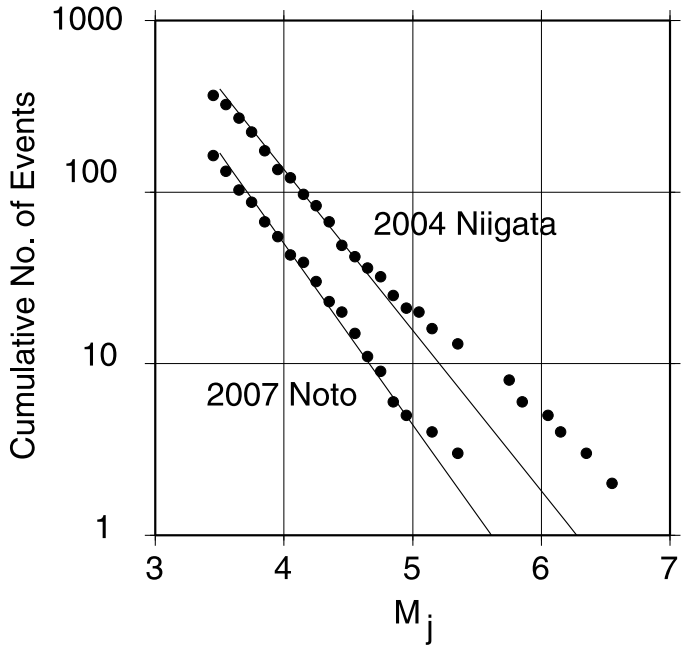

Fig. 4. Frequency-magnitude distributions of the 2004 Niigata and 2007 Noto earthquakes for 10 days following the mainshocks. Lines show $b$-values of 0.94 and 1.05 for the Niigata and Noto events, respectively.

the $c$-value for Niigata may also be rather short. This estimate is somewhat shorter than the $c$-value of 4.3 minutes that was obtained by Enescu et al. (2007) for the Niigata earthquake by fitting data for about 70 days.

\section{Discussion}

The results showing that the early aftershock sequences were initially similar for the two earthquakes, suggest that initial conditions at the times of the mainshocks were the same. Then, there was a change in the Niigata region about 5 to 10 minutes after the mainshock that promoted the el- 
evated occurrence of aftershocks. There was no obvious clustering of the locations of the aftershocks, so the increased level of activity extends throughout the aftershock region. The difference in the frequency-magnitude distributions (Fig. 4) also indicates that the triggered events were relatively larger for Niigata.

Even though the Niigata sequence had an unusual number of larger aftershocks, the observed higher rate of seismicity probably cannot be simply explained by just adding up the aftershocks for the mainshock plus the secondary sequences for the larger aftershocks, as has been suggested by Aoki et al. (2005). The moment of the mainshock is $1.0 \times 10^{19} \mathrm{~N}$ m and the combined moment of the mainshock plus four largest aftershocks is $1.6 \times 10^{19} \mathrm{~N} \mathrm{~m}$. In comparison, the moment of the Noto earthquake is $1.4 \times 10^{19} \mathrm{~N} \mathrm{~m}$. The combined moments of the two sequences differ by less than 15 percent, but the rates of aftershocks are different by about a factor of 3 .

Another indication of the enhanced triggering in the Niigata region, is that in our data set there are more identified aftershocks during the 5 minutes following the $M_{\mathrm{j}} 6.3$, $M_{\mathrm{j}} 6.0$, and $M_{\mathrm{j}} 6.5$ events, compared to the 5 minutes following the mainshock (Fig. 3). However, this comparison needs to be checked more carefully since the primary aftershocks of the mainshock are included in the secondary aftershocks of the $M 6$ events. Also, there is still a detection problem for the first minute following the mainshock.

The change in the aftershock level for the Niigata sequence corresponds to the occurrence of a $M_{\mathrm{j}} 6.3$ event about 7 minutes after the mainshock. This might suggest that the aftershock might have been the cause of some change in the source region. However, it is difficult to image a change over the entire source region which is due to the shaking of this aftershock, since the shaking is much less than the mainshock. Therefore, we think that the occurrence of the $M_{\mathrm{j}} 6.3$ aftershock is a symptom of changes in the fault zone, rather than the cause of the changes.

What is the cause of the enhanced triggering for the Niigata sequence? There is no indication of any large aseismic slip soon after the mainshock. The Niigata region is an area of hydrocarbon production with regions of high pressure fluids, and Sibson (2007) proposes that the swarm-like behavior is due to upward discharge of fluids from a deeper overpressured region. Prior to the earthquake, there was evidence for overpressured fluids from borehole data and local effusions of saline water along mapped fault traces in the region (Xu et al., 2006). Fluid may flow into openings of fault zones caused by strong earthquake shaking, resulting in a reduction of the normal stresses on the faults. Alternatively, shaking may clear pathways (Brodsky, 2006) allowing pore pressure conditions to change in the fault zone.

These results show that there are local differences that can control aftershock activity. Peng et al. (2007) looked at the aftershock sequences for many smaller events in Japan, and found a wide range of $p$-values. One characteristic they noted was a change in aftershock rate several minutes after the mainshock, which is similar to our results for the Niigata earthquake.

\section{Conclusions}

Examination of the early aftershock sequences of the 2004 Mid-Niigata and 2007 Noto Hanto earthquakes showed that the level of seismicity was very similar for the first 7 minutes. Following this time the triggering of aftershocks was much enhanced in the Niigata region, as shown by the greater number of larger aftershocks and the stronger secondary aftershocks sequences. This change might be associated with fluid movements into the fault zone.

Acknowledgments. We thank the National Institute for Earth Science and Disaster Prevention for the use of the Hi-Net data and the Japanese Meteorological Agency for the hypocenter catalog. This work was partially supported by the Kyoto University Geosphere Investigations for the 21st Century Centers of Excellence Program. BE acknowledges support from EC-FP6-project SAFER.

\section{References}

Aki, K., Maximum likelihood estimate of $\mathrm{b}$ in the formula $\log \mathrm{N}=\mathrm{a}-\mathrm{bM}$ and its confidence limits, Bull. Earthquake Res. Inst. Univ. Tokyo, $\mathbf{4 3}$ 237-239, 1965.

Aoki, S., M. Nishi, K. Nakamura, T. Hashimoto, S. Yoshikawa, and H. Ito, Multi-planar structures in the aftershock distribution of the Mid-Niigata prefecture earthquake in 2004, Earth Planets Space, 57, 411-416, 2005.

Brodsky, E. E., Long-range triggered earthquakes that continue after the wavetrain passes, Geophys. Res. Lett., 33, L15313, doi:10.1029/ 2006GL026605, 2006.

Enescu, B., J. Mori, and M. Miyazawa, Quantifying early aftershock activity of the 2004 mid-Niigata Prefecture earthquake $\left(M_{w} 6.6\right), J$. Geophys. Res., 112, doi:10.1029/2006JB004629, 2007.

Gutenberg, B. and C. F. Richter, Frequency of earthquakes in California, Bull. Seismol. Soc. Am., 34, 185-188, 1944.

Kagan, Y. Y., Short-term properties of earthquake catalogs and models of earthquake source, Bull. Seismol. Soc. Am., 94, 1207-1228, 2004.

Mori, J. and P. Somerville, 2004 Niigata-ken, Chuestu EarthquakeSeismology and Strong Ground Motions, Earthquake Spectra, 22, S9S21, 2006.

Peng, Z., J. E. Vidale, and H. Houston, Anomalous early aftershock decay rate of the 2004 Mw6.0 Parkfield, California earthquake, Geophys. Res. Lett., 33, doi:10.1029/2006GL026744, 2006.

Peng, Z., J. E. Vidale, M. Ishii, and A. Helmstetter, Seismicity rate immediately before and after main shock rupture from high-frequency waveforms in Japan, J. Geophys. Res., 112, doi:10.1029/2006JB004386, 2007

Shcherbakov, R., D. L. Turcotte, and J. B. Rundle, A generalized Omori's law for earthquake aftershock decay, Geophys. Res. Lett., 31, doi:10. 1029/2004GL019808, 2004.

Sibson, R. H., An episode of fault-valve behavior during compressional inversion?-The $2004 M_{\mathrm{j}} 6.8$ Mid-Niigata Prefecture, Japan earthquake sequence, Earth Planet. Sci. Lett., 257, 188-199, 2007.

Utsu, T., A statistical study on the occurrence of aftershocks, Geophys. Mag., 30, 521-605, 1961.

Xu, H. L., J.-W. Shen, and X.-W. Zhou, Geochemistry of geopressured hydrothermal waters in the Niigata sedimentary basin, Island Arc, 15, 199-209, 2006.

J. Mori (e-mail: mori@eqh.dpri.kyoto-u.ac.jp), Y. Kano, and B. Enescu 